\title{
A Review: Using Simulation-based Education to Substitute Traditional Clinical Rotations
}

\author{
Lori Persico* \\ Clinical Education Specialist, Patient Safety Institute, Center for Learning \& Innovation, New York, USA
}

Submission: August 11, 2018; Published: August 23, 2018

*Corresponding author: Lori Persico, Hofstra Northwell School of Graduate Nursing and Physician Assistant Studies, 1979 Marcus Ave $\backslash \mathrm{r} \backslash \mathrm{nSuite}$ 101\r\nLake Success, New York 11042, USA,Tel: 5163966150; Email: Ipersico@nshs.edu

\begin{abstract}
Nursing programs are challenged with limited clinical placement, and a shortage of faculty. Curricular objectives are increasingly difficult to achieve as the traditional clinical setting impairs the ability to meet high-quality clinical experiences for pre-licensure nursing students due to the lack of access to patient care areas, hence making it difficult to achieve learning objectives and program outcomes. A solution supported by the literature is to substitute traditional clinical rotations with simulated clinical events. Although simulation-based education has been adopted by nursing programs as a teaching strategy for clinical instruction, the effectiveness of SBE remained inconclusive in the literature. Research is focused on students â€ perceived learning, satisfaction with simulation, self-confidence and self-efficacy ratings. Scarcity is evident in the quantitative evidence of the effectiveness of simulation-based education. Nursing practice is dependent on critical thinking and clinical reasoning skills. Learning is not be optimized without standardization of simulated clinical rotations and the lack of rigor for the measurement of learning. Best Practices are outlined by the International Nursing Association for Clinical Simulation and Learning and the National Council of State Boards for Nursing for training and education of faculty. The implementation of simulation-based education and its outcome on learning remains limited in the literature. This article summarizes research, best practices and accrediting agenciesâ $€^{\mathrm{TM}}$ recommendations.
\end{abstract}

\section{Introduction}

Nursing practice requires an understanding of health, diseases, and management to demonstrate competent technical skills, critical thought processes, time management, and other nursing responsibilities Bashford, Shaffer \& Young [1]. Simulationbased education mimics patient responses. Students can practice and develop cognitive, moto, and clinical reasoning skills in a safe environment. SBE curriculum is a range of active learning activities that includes simple to complex methods such as concept mapping, task- trainers,high fidelity human patient simulators, standardized patients, and computerized instruction CannonDiehl [2], McGaghie, Issenberg, Petrusa,Scalese [3], Dearmon et al. [4].Nursing programs are challenged with providing high-quality clinical experiences for students. It has become increasingly difficult to utilize clinical experiences to promote critical thinking and clinical judgment due to a growing shortage of nursing faculty and limited clinical placements. Clinical objectives are further impinged upon when the clinical setting does not meet the outcomes outlined in nursing curricula. Facilities may not grant the student full access to the electronic medical record. In addition, patient safety initiatives may decrease the number of students permitted on a patient care unit or students may be restricted to an observational experience. Simulation- based education (SBE) is a teaching strategy that can overcome the barriers of clinical instruction for prelicensure nursing students. Although nursing programs have adopted simulation as a teaching strategy for clinical instruction, the effectiveness of SBE has remained inconclusive in the literature.

\section{Review of the Literature}

Early simulation research studies focused on students 'perceived learning, satisfaction with simulation, self-confidence and self-efficacy ratings (Alinier, Hunt, \& Gordon, 2004; Alinier, Hunt, Gordon \& Harwood [5]; Bearson\&Wiker [6]; Bremner, Aduddell, Bennett, \&VanGeest [7], Brown \& Chronister [8], Childs \&Sepples [9]; Cant \& Cooper [10], Jefferies \&Rizzolo 2006; Nehring 2004; Schoening, Sittner and Todd [11]; Sherer, Bruce \&Runkawatt [12]; Kuiper, Heinrich, Matthias, Graham \& Bell-Kotwall [13]. Researchers examined critical thinking and the impact simulation had on students' knowledge, however, the results were inconclusive Jefferies\&Rizzolo [14], Kardong-Edgren, Anderson \& Michaels [15]; Ravert [16], Ruggenberg [17]. Berndt's [18] integrative review of undergraduate programs found 17 studies and three systematic reviews with evidence clearly supporting the use of simulation as an educational intervention to teach patient safety competencies in prelicensure nursing education. However, some research designs were not rigorous.

Few studies showed quantitative evidence of the effectiveness of simulation-based education. Alinier, Hunt, Gordon and Harwood 
[5] conducted a study of three consecutive cohorts of prelicensure students to determine the effects of simulation on clinical skills and competence. The pre-test/posttest study compared simulation versus none using the Objective Structured Clinical Examination (OSCE) assessment tool. The test scores for the simulation group improved and achieved statistical significance.Meyer, Connors and Gajewski (2011) measured clinical performance. A convenience sample of 116 junior nursing students enrolled in a pediatric course had $25 \%$ of clinical time replaced with simulation-based education. The eight-week course had two weeks of traditional clinical time (25\%). The students spent the same amount of time in simulation as in clinical, 12 hours per week in simulation. Clinical faculty measured students' clinical performance. Simulation groups derived from five clinical groups and every two weeks students were selected from each clinical group. The twoweek program had four simulation sessions that contained two pediatric scenarios. Students with a simulated clinical had higher scores than participants in the traditional clinical area.Simulationbased education enables the application and development of clinical reasoning. Studies found that simulation experiences assist students' ability to synthesize knowledge and apply it to clinical practice. Sportsman, Schumacker and Hamilton [19] descriptive and longitudinal study found that nursing students were able to learn unique skills and knowledge not found in the traditional clinical setting. Lapkin, Levett-Jones, Bellchambers and Fernandez [20] performed a meta-analysis of simulation outcomes and discovered that SBE improved components of clinical reasoning, critical thinking, knowledge, and the ability to recognize a deteriorating clinical condition of a patient.

Noted in the researcher are methodological challenges. Instruments lack validity and reliability have a small effect size, and face criticism with the use of self-report Cant \& Cooper [10]. Randomization, large sample size and power are scarce in simulation researchShinnick, Woo \&Mentes [21], Weaver [22], Foronda, Liu \& Bauman [23]. Further systematic and integrative reviews of the science could not establish the relationship between high fidelity simulation and learning in undergraduate nursing education Blum \& Parcells [24]; Fisher \& King [25]; Foronda, Liu \& Bauman [23]; Yuan, Williams \& Fang [26]. These findings are not limited to nursing, similar issues are identified in health care literature Cook et al. [27]. A review of 34 years of the medical simulation literature reached the same conclusion andneeds to improve in its rigor and quality because high-fidelity education is an effective compliment to medical education and patient care McGaghie, Issenberg, Petrusa\&Scalese [3].

In an effort to standardized practice in simulation the International Nursing Association for Clinical Simulation and Learning (INACSL), 2013, 2015) published guidelines. Best practices center on simulation design, measurement of outcomes, and development of objectives, facilitation, debriefing, evaluation, professional integrity, simulation-enhanced interprofessional education and a simulation glossary. Criterions are evident for each individual standard. Guidelines provide a detailed process for evaluating and improving simulation operating procedures and delivery methods. The aim is to advance the science of simulation, share best practices, and provide evidence-based guidelines for implementation and training.

\section{Replacing Clinical Rotations with Simulation-Based Education}

Clinical simulations can bridge the gap between knowledge gained in the classroom and clinical practice with patients. Using technology, learners interact in authentic, replicated clinical situations, engage in independent decision-making, and see the results of their actions without causing harm to real patients Gaba [28]; Kaddoura [29]. In 2014, the National Council of State Boards of Nursing (NCBSN) released the results of a landmark study. Traditional clinical instruction was substituted with simulated clinical experiences. The study definessimulation as, "An activity or event replicating clinical practice using scenarios, high-fidelity manikins, medium-fidelity manikins, standardized patients, role playing, skills stations, andcomputer-based critical thinking simulations Hayden, Jeffries, Kardong-Edgren \& Spector [30].

The 2014 NCBSN study lead by Hayden, Smiley and Gross included over 600 hundred prelicensure registered nurses (RN) from associate and baccalaureate nursing programs. The study spanned over two years across seven clinical courses, these were fundamentals, adult health, and maternal-newborn, nursing care of children, mental health, and community health nursing. Ten pre-licensure programs across the United States were randomized into one of three study control groups. The control group had traditional clinical experiences, meaning no more than 10 percent of clinical hours could be spent in simulation. The second group had 25 percent of clinical hours spent in simulation and the third had 50 percent. Reliable and valid instruments measured students' clinical competency, nursing knowledge, and rated how learning objectives were met in the clinical and simulated environments.

Multiple domains of learning were stimulated using a variety of simulation teaching strategies. Simulated clinical experiences involved medium or high-fidelity manikins, standardized patients, role-playing, skill stations, and computer based critical thinkingsimulations. According to Hayden [31], students rotated through the stations and simulated scenarios were used to observe higher-order cognitive processes and less of psychomotor skill evaluation. Simulated scenarios followed the Nation League of Nursing (NLN) /Jefferies Simulation Framework (2012) (Figure1). Observation of clinical performance was performed. Clinical instructors evaluated students' performance each week of clinical and after every simulation scenario.The Debriefing for Meaningful Leaning was used to debrief students@Dreifuerst [32]. Clinical instructors facilitated traditional and simulated clinical rotations. Debriefing was performed by members of the study team. 




Figure 1

The research studied students 'clinical competency and nursing knowledge and rated how learning objectives were met in the clinical and simulated environments. The instrument used to measure knowledge outcomes were the ATI Content Mastery Series® (Assessment Technologies Institute, LLC) (CMS) and ATI RN Comprehensive Predictor ${ }^{\circledR}$ exam. The Creighton Evaluation Instrument (CCEI) measured clinical competency. Three instruments comprised the End-of-Program Preceptor Survey, those included were the New Graduate Performance Survey (NGNPS), the Global Assessment of Clinical Competency and Readiness for Practice and Critical Thinking Diagnostic(C) to assess students' ability to critically think, prioritize, and problem solve in a clinical setting. The Clinical Learning Environment Comparison Survey (CLES) measuredstudents' perceptions of how learning was met. National Council Licensure Examination (NCLEX $®)$ scores determined competency for the entry-level RN.Results for the three groups showed no statistical differences between the three groups in the clinical competency as assessed by clinical preceptors and instructors $(p=0.688)$ differences in the comprehensive nursing knowledge assessments $(p=0.478)$, and in NCLEX passrates $(\mathrm{p}=0.737)$. The study followed the groups six months into clinical practice.Follow-up surveys were sent to
Nurse Managers at six weeks, three months, and six months of employment. The survey rated clinical competency and readiness for practice. There were no statistical differences between the three groups at the six-week $(p=0.706)$, three months $(p=0.511)$ and six months $(\mathrm{p}=0.527)$ timeframes. NCLEX passing rates did not differ between prelicensure nursing students who spent 25 or 50 percent in simulation versus traditional clinical.

Limitations to the NCBSN study were the schools were not randomly selected, clinical instructors; preceptors and nurse manager were not blinded to the participants. Students in the study were responsible for sending electronic follow-up surveys to clinical instructors, preceptors, and managers. The findings in this study confidently advocates substituting up to 50 percent simulation for clinical experiences promote outcomes similar to traditional clinical experiences. Faculty are to be adequately trained, committed, and in sufficient numbers.Nursing programs need to have a dedicated simulation lab with appropriate human and technological resources. Clinical scenarios or vignettes are to be and designed to realisticallyrepresent the patient's problem and utilize a debriefing approach based on a theoretical model Alexander et al. [33].

Table 1

NCSBN Guidelines-Program Preparation Checklist

1. The school creates a framework that provides adequate resources (fiscal, human, and material) to support the simulation.

2. Policies and procedures are in place to ensure quality-consistent simulation experiences for the students.

3. The simulation program has an adequate number of dedicated trained simulation faculty members to support the learners in simulation-based experiences.

4. The program has job descriptions for simulation faculty members/facilitators.

5. The program has a plan for orienting simulation faculty members to their roles.

6. The program uses a needs assessment to determine what scenarios to use.

7. The simulation program provides subject-matter expertise for each scenario debriefing.

8. The program and faculty members incorporate the INACSL Standards of Best Practice: Simulation.

9. The program has appropriate designated physical space for education, storage,and debriefing. 
10. The faculty members have a process for identifying what equipment or relevanttechnologies needed for meeting program objectives.

11. The program has adequate equipment and supplies to create a realistic patient care environment.

12. The faculty use evaluative feedback for quality improvement of the simulation program.

13. The administration has a long-range plan for the use of simulation in the future.

An expert panel from INACSL, NCSBN, American Association for Colleges of Nursing, and National League for Nursing (NLN), Society for Simulation and Healthcare, and State Board of Nursing (BON) used the data from the NCSBN Study to develop national guidelines for use in simulation in the undergraduate nursing curriculum. The goal of the guidelines are to assist BONs to evaluate the readiness of prelicensure nursing programs in using simulation in place of traditional clinical settings and to aid academic institutions in the development of evidence- based simulation programs for undergraduate students Alexander et al. [33]. NCSBN established checklists for program preparation (Table 1) and faculty development(Table 2).

\section{Table 2}

\section{NCSBN Guidelines -Preparation of Faculty}

1. The simulation program is based on educational theories associated with simulation, such as experiential learning theory. 2. INACSL Standards of Best Practice for simulation are used to prepare faculty members are

3. A tool for evaluating simulation-based learning experiences is designed based on the INACSL Standards of Best Practice: Simulation evaluation methods.

4. The program curriculum sets clear objectives and expected outcomes for each simulation- based experience,

5. The program has established a method of sharing student performance with clinical faculty.

6. The program collects and retains evaluation data regarding the effectiveness of the facilitator.

7. The program collects and retains evaluation data regarding the effectiveness of the simulation experience.

8. The program provides a means for faculty members to participate in simulation-related professional development, such as webinars, conferences, journals, clubs, readings, and certifications such as Certified Health Care Simulation Educator, and participation in NLN Sim Leaders/Sigma Theta Tau International Nurse Faculty Leadership Academy with a focus on simulation.

Hayden, Smiley and Gross [31]conducted a descriptive survey to document state regulations and to provide a benchmark for regulatory agencies. The Nursing National Simulation sent surveys to Executive Officers and addressed current regulations for the use of simulation in place of traditional clinical time and the maximum amount of simulation allowed in the nursing curriculum. Sixty-one surveys out of 66 jurisdictions that regulate registered nurses provided data. Only four states specified the regulations on the maximum amount of simulation hours that can replace traditional clinical hours. California, Florida, Vermont, and Virginia stipulated up to 25 percent of clinical hours could be replaced with simulation-based education SBE (Table 3). Remaining states were silent or did not specify the amount of clinical hours or approved SBE in a case-by case method. Some states allowed schools to determine the number of hours substituting for traditional clinical hours with SBE. A standard for substitutionratio for simulation hours to traditional clinical hours does not exist among prelicensure nursing programs Breymier et al. [34]. National consensus is not evident in the nursing profession, this as to the amount of clinical time is replaced with simulation-based education.Phase two of the study surveyed over one thousand nursing programs. Results indicate simulation use is inhibited due to the limited amount of faculty trained to perform simulation- based education. There is a lack of funding to train faculty and to increase simulation use.

\section{Table 3}

\begin{tabular}{|c|c|c|}
\hline State & $\begin{array}{c}\text { Maximum Amount of Simulation Allowed to Replace Clinical Time for } \\
\text { RN Programs }\end{array}$ & Stipulations \\
\hline California & Up to 25\% & 75\% of clinical hours must be in direct patient care \\
\hline Florida & Up to $25 \%$ & None \\
\hline Vermont & Up to 25\% & None \\
\hline Virginia & Up to 50\% per course, not to exceed 20\% in the entire program & Recent BON proposal to limit simulation to 25\% \\
\hline
\end{tabular}

Undergraduate programs ( $\mathrm{N}=379)$ continue to use simulation as a teaching strategy in the curriculum. Pre-purchased highfidelity medical surgical and emergent scenarios are more frequently used; over 80 percent would incorporate more manikinbased simulation into the curriculum. The reported non-manikin- based simulation methods were CD-ROM programs (54\%), standardized patients (36\%), and inter-based virtual hospital (25\%), virtual IV (34\%), Second Life (5\%), Virtual Neighborhood (5\%), and other (16\%). Program evaluation centers on students and faculty perception of the quality of scenario content. 


\section{State of the Science}

Doolen et al. [35] performed a review of simulation reviews from 2009 to 2015 for high-fidelity simulation in undergraduate nursing education. The comprehensive review utilized databases and found 34 reviews, but only seven reviews met the review criteria. Articles were appraised using the Critical Appraisal Skills Program guidelines; the survey evaluates research studies. Of the seven reviews, five were integrative and two were reviews of the literature.Results remain similar; research studies did not attain quality and rigor. Findings show significant differences in design and assessment methods leading to a wide variety of measurement outcomes and a variety of limitations. The current state of the science in simulation-based research calls for intervention studies that examine skill development, skill transfer, and higher order thinking from simulationto actual patient care settings to support positive health outcomes in patients Cantrell \&Mariani [36]. There is deficiency in the quantitative evidence of effectiveness for simulation- based education and its transferability to nursing practice Shinnick, Woo \&Mentes [21], Hayden, Smiley, Alexander, Kardong-Edgren \& Jefferies [31],Marini Doolen et al. [35].

\section{Recommendations}

Clinical placements and faculty resources are becoming increasingly limited for nursing programs. Literature supports the solution to exchange tradition clinical rotations with simulated clinical experiences. Simulation-based education for clinical practice incorporates task trainers, standardized patients and highfidelity simulation. This continuum helps to develop clinical reasoning by stimulating all domains of learning and applying it a safe environment.According to Rutherford, Lioce, KardongEdgren, Jefferies and Sittner [37]nursing programs are to have a shared mental model for a simulation-based education program and training of simulation the faculty. Interchanging simulationbased education with traditional requires a dedicated team. It is a collaboration of faculty, laboratory staff, clinical faculty, and the simulation team. INACSL standards are evidenced-based practices used to frame the instruction of educators and program development along with NCSBN guidelines program preparation checklist. To ensure standards and curriculum are upheld, a simulation committee representing faculty, laboratory staff, clinical Instructors, simulationists and students.

Curriculum designed and developed by the faculty are to determine the content translated into a simulation educational session. Clinical instructors are necessary resource for simulated clinical scenarios because of the specialized skill set. Clinical instructors are experts imparting knowledge about nursing process, physical assessment and evidence-based practice. Laboratory staff is necessary for the development of nursing skills with the use of task trainers. Dedicated simulation experts help develop faculty in the knowledge of scenario writing, use of technology, debriefing, logistics, research and design and measurement of learning outcomes.
Traditional clinical rotations involve faculty performing students' observations of clinical practice. Nursing students are to apply the nursing process and institute evidenced based practices safely. Evaluation instruments measure critical actions and ensure learning outcomes are met. The same evaluation process is considered and implemented with simulated clinical experiences[38-40].

Measuring self-reporting of satisfaction and learning saturates the simulation literature and does not ensure safe clinical practice. Simulation literature calls for more randomized studies with reliable and validated instruments.Lastly, use of clinical simulation focuses on nursing practice, a profession that is reliant on other disciplines for the best patient outcomes. When considering introducing or replacing traditional clinical rotations with simulation experiences, nursing programs are to consider the interprofessional approach to patient care. Working in silos creates communication failures and impairs patient safety. Interprofessional education models lead to role comprehension, enhanced communication and better teamwork. Sanctioning multiple healthcare professionals to learn together establishes roles, teams and communication, thereby increasing the potential to improve patient outcomes in both the community and the acute care setting.

\section{References}

1. Bashford CW, Shaffer BJ, Young CM (2012) Assessment of clinical judgment in nursing orientation. Journal for Nurses in Staff Development 28(2): 62-65.

2. Cannon Diehl MR (2009) Simulation in healthcare and nursing: State of the science. Critical care nursing quarterly 32(2): 128-136.

3. McGaghie WC, Issenberg SB, Petrusa ER, Scalese RJ (2010) A critical review of simulation-based medical education research: 2003-2009. Medical education 44(1): 50-63.

4. Dearmon V, Graves RJ, Hayden S, Mulekar MS, Lawrence SM, et al. (2012) Effectiveness of simulation-based orientation of baccalaureate nursing students preparing for their first clinical experience. Journal of Nursing Education 52(1): 29-38.

5. Alinier G, Hunt B, Gordon R, Harwood C (2006) Effectiveness of intermediate- fidelity simulation training technology in undergraduate nursing education. Journal of advanced nursing 54(3): 359-369.

6. Bearnson CS, Wiker KM (2005) Human patient simulators: A new face in baccalaureate nursing education at Brigham Young University. Journal of Nursing Education 44(9): 421-425.

7. Bremner MN, Aduddell K, Bennett DN, VanGeest JB (2006) The use of human patient simulators: Best practices with novice nursing students. Nurse Educator 31(4): 170-174.

8. Brown D, Chronister C (2009) The effect of simulation learning on critical thinking and self-confidence when incorporated into an electrocardiogram nursing course. Clinical Simulation in Nursing 5(1): e45-e52.

9. Childs JC, Sepples S (2006) Clinical teaching by simulation: Lessons learned from a complex patient care scenario. Nursing Education Perspectives 27(3): 154-158.

10. Cant RP, Cooper SJ (2009) Simulation-based learning in nurse education: systematic review. Journal of advanced nursing 66(1): 3-15. 
11. Schoening AM, Sittner BJ, Todd MJ (2006) Simulated clinical experience: Nursing students' perceptions and the educators' role. Nurse educator 31(6): 253-258.

12. Scherer YK, Bruce SA, Runkawatt V (2007) A comparison of clinical simulation and case study presentation on nurse practitioner students' knowledge and confidence in managing a cardiac event. International Journal of Nursing Education Scholarship 4(1).

13. Kuiper R, Heinrich C, Matthias A, Graham MJ, Bell Kotwall L (2008) Debriefing with the OPT model of clinical reasoning during high fidelity patient simulation. International Journal of Nursing Education Scholarship 1-13.

14. JeffriesPR, RizzoloMA(2006)Designing and implementing models for the innovative use of simulation to teach nursing care of ill adults and children: A national multi- site, multi-method study. New York, NY: National League for Nursing.

15. Kardong Edgren S, Anderson M, Michaels J (2007) Does simulation fidelity improve student test scores? Clinical Simulation in Nursing 3(1): e21-e24.

16. Ravert PKM(2004) Use of a Human Patient Simulator with Undergraduate Nursing Students: A rototype Evaluation of Critical Thinking and Self-Efficacy. PhD thesis, The University of Utah, Salt Lake City, UT.

17. Ruggenberg S(2008) The Effect of Simulated Clinical Experience on Knowledge, Near Transfer, and Far Transfer in Nursing Education. EdD thesis, University of San Francisco, San Francisco, CA.

18. Berndt J (2014) Patient safety and simulation in prelicensure nursing education: An integrative review. Teaching and Learning in Nursing $9(1): 16-22$

19. Sportsman S, Schumacker RE, Hamilton P (2011) Evaluating the Impact of Scenario-Based High-Fidelity Patient Simulation on Academic Metrics of Student Success. Nursing Education Perspectives 32(4): 259-265

20. Lapkin S, Levett Jones T, Bellchambers H, Fernandez R (2010) Effectiveness of patient simulation manikins in teaching clinical reasoning skills to undergraduate nursing students: A systematic review. Clinical simulation in nursing 6(6): e207-e222.

21. Shinnick MA, Woo MA, Mentes JC (2011) Human patient simulation: State of the science in prelicensure nursing education. Journal of Nursing Education 50(2): 65-72.

22. Weaver AMY (2011) High-Fidelity Patient Simulation in Nursing Education: An Integrative Review. Nursing Education Perspectives 32(1): 37-40.

23. Foronda C, Liu S, Bauman EB (2013) Evaluation of simulation in undergraduate nurse education: An integrative review. Clinical Simulation in Nursing 9(10): e409-e416.

24. Blum CA, Parcells DA (2012) Relationship between high-fidelity simulation and patient safety in a prelicensure nursing education: A comprehensive review. Journal of Nursing Education 51(8): 429-435.
25. Fisher D, King L (2013) An integrative literature review on preparing nursing students through simulation to recognize and respond to the deteriorating patient. Journal of Advanced Nursing 69(11):2375-2388.

26. Yuan HB, Williams BA, Fang JB (2012) The contribution of high fidelity simulation to nursing students' confidence and competence: A systematic review. International Nursing Review 59(1): 26-33.

27. Cook DA, Hatala R, Brydges R, Zendejas B, Szostek JH, et al. (2011) Technology-enhanced simulation for health professions education: a systematic review and meta-analysis. Jama 306(9): 978-988.

28. Gaba DM (2004) The future vision of simulation in health care. Quality and Safety in Health Care 13(1): i2-i10.

29. Kaddoura MA (2010) New graduate nurses' perceptions of the effects of clinical simulation on their critical thinking, learning and confidence. Journal of Continuing Education in Nursing 41(11): 506-516.

30. Hayden JK, Jeffries PJ, Kardong-Edgren S, Spector N (2009) The National Simulation Study: Evaluating simulated clinical experiences in nursing education. Unpublished research protocol. National Council of State Boards of Nursing, Chicago IL 5(2): S3-S40.

31. Hayden JK, Smiley RA, Gross L (2014) Simulation in nursing education: current regulations and practices. Journal of Nursing Regulation 5(2): 25-30.

32. Dreifuerst KT (2015) Getting started with debriefing for meaningful learning. Clinical Simulation in Nursing 11(5): 268-275.

33. AlexanderM, DurhamCF, HooperJI, JeffriesPR, GoldmanN, et al. (2015) NCSBN simulation guidelines for prelicensure nursing programs. Journal of Nursing Regulation6(3): 39-42.

34. Breymier TL, Rutherford-Hemming T, Horsley TL, Atz T, Smith LG, et al. (2015) Substitution of clinical experience with simulation in prelicensure nursing programs: A national survey in the United States. Clinical Simulation in Nursing 11(11): 472- 478.

35. Mariani B, Doolen J (2016) Nursing simulation research: What are the perceived gaps?. Clinical Simulation in Nursing 12(1): 30-36.

36. Cantrell MA, Mariani B (2016) Moving the Research Agenda Forward in Simulation-Based Research. Clinical Simulation in Nursing 12(11): i-ii.

37. Rutherford Hemming T, Lioce L, Jeffries PR, Sittner B (2016) After the National Council of State Boards of Nursing Simulation Studyrecommendations and next steps. Clinical Simulation in Nursing 12(1): 2-7.

38. Dreifuerst KT (2010) Debriefing for meaningful learning: Fostering development of clinical reasoning through simulation. Indiana University.J Nurs Educ 51(6): 326-333.

39. International Nursing Association of Clinical Simulation and Learning Standards Committee. (2013; 2015). Standards of best practice in simulation I-IX. Clinical Simulation in Nursing9(6S): S1-S35.

40. JeffriesPR, RogersKJ(2012)Theoretical framework for simulation design. In PRJeffries (Ed.), Simulation in nursing education from conceptualization to evaluation,p. 25-41. 
This work is licensed under Creative Commons Attribution 4.0 License
DOI: $10.19080 / J O J N H C .2018 .09 .555762$

\section{Your next submission with Juniper Publishers will reach you the below assets}

- Quality Editorial service

- Swift Peer Review

- Reprints availability

- E-prints Service

- Manuscript Podcast for convenient understanding ain

- Global attainment for your research

- Manuscript accessibility in different formats ( Pdf, E-pub, Full Text, Audio)

- Unceasing customer service

Track the below URL for one-step submission https://juniperpublishers.com/online-submission.php 